\title{
Correlation of maximum oxygen consumption with component composition of the body, body mass of men with different somatotypes aged $25-35$
}

Viacheslav M. Miroshnichenko ${ }^{1 \mathrm{ABCDE}}$, Yuriy M. Furman ${ }^{1 \mathrm{ABCD}}$, Oleksandra Yu. Brezdeniuk ${ }^{1 \mathrm{ABCD}}$ Victoria E. Onyshchuk ${ }^{1 \mathrm{ABCD}}$, Natalia V. Gavrylova ${ }^{1 \mathrm{ABCD}}$, Svitlana V. Salnykova ${ }^{2 \mathrm{ABCD}}$

${ }^{1}$ Vinnytsia Mykhailo Kotsiubynskyi State Pedagogical University, Ukraine

${ }^{2}$ Vinnytsia Institute of Trade and Economics of Kyiv National University of Trade and Economics, Ukraine

Authors' Contribution: A - Study design; B - Data collection; C - Statistical analysis; D - Manuscript Preparation; E - Funds Collection.

\section{Abstract}

Purpose:

The somatotype determines not only physical development, but also the functional capabilities of the organism. Investigation of the correlation relations between the component of body and $\mathrm{VO}_{2 \max }$ will reveal the influence of each of the components on the aerobic capacity of men in the first period of mature age. The aim of the work - to detect the peculiarities of manifestation of maximum oxygen consumption of men with different somatotypes and to investigate the relationship with the component composition of the body.

Material: $\quad$ The study involved 150 men aged 25-35 years. The somatotype was determined by the Heath-Carter method. The component composition of the body was determined by the bioelectrical impedance method. The $\mathrm{VO}_{2 \max }$ indicator was determined, metered loads were performed on a bicycle ergometer. A correlation analysis of the absolute and relative $\mathrm{VO}_{2 \max }$ values with the fat and muscle components of the body was performed.

Results: $\quad$ A high degree of inverse correlation between the relative $\mathrm{VO}_{2 \text { max }}$ indicator with body mass in men of mesomorphic somatotype was established and a high degree of inverse correlation between the relative $\mathrm{VO}_{2 \max }$ indicator with body mass and $\mathrm{BMI}$ in men of endomorphic-mesomorphic somatotype.

Conclusions: $\quad$ For representatives of the mesomorphic and endomorphic-mesomorphic somatotype, a larger body mass and a high degree of correlation between body mass and relative $\mathrm{VO}_{2 \max }$ indicator are characteristic. For representatives of the ectomorphic and balanced somatotype, a smaller body mass and a lower degree of correlation between body mass and relative $\mathrm{VO}_{2 \text { max }}$ indicator max are characteristic.

Keywords: aerobic capacity, muscular, fat component, men.

\section{Introduction}

The somatotype determines not only physical development, but also the functional capabilities of the organism [1]. The level of functional capabilities is due to its energy potential. In the overall energy potential of a man, aerobic energy is largely preponderate anaerobic energy. The power of aerobic processes of energy supply muscular activity reflects the maximum oxygen consumption indicator $\left(\mathrm{VO}_{2 \text { max }}\right)$. Our previous researches have revealed the peculiarities of manifestation of maximum oxygen consumption in students aged 17-19 with different somatotype [2]. We also researched the level of aerobic capabilities of youth 17-19 years old living within the Podillya region [3]. Yoo-Rim Choi \& Wan-Suk Choi point to the revealed features of maximum oxygen consumption among students of different somatotypes [4]. Goran Spori et al found significant differences in the $\mathrm{VO}_{2 \max }$ values among Personnel of the Croatian Navy of different somatotypes [5]. The negative influence of endomorphy on the aerobic capabilities of men and women from Kuwait was revealed by Alkandari \& Barac

\footnotetext{
(c) Viacheslav M. Miroshnichenko, Yuriy M. Furman,

Oleksandra Yu. Brezdeniuk, Victoria E. Onyshchuk,

Natalia V. Gavrylova, Svitlana V. Salnykova., 2020

doi:10.15561/26649837.2020.0603
}

Nieto [6] and Rupasinghe et al [7]. We did not find scientific publications about the differences in absolute and relative $\mathrm{VO}_{2 \text { max }}$ values in men of the first mature age of different somatotypes.

There are publications that prove body components decisive influence on human functional capabilities. Sukanta Saha found that the component composition of the body is well correlated with $\mathrm{VO}_{2 \max }$ [8]. Manmohan Sharma et al found the negative effects of the fat component on the aerobic capacity of men 25-35 years old. The authors established a correlation between $\mathrm{VO}_{2 \max }$ and body mass index (BMI), the ratio of the circumferential waist size to the thigh and the percentage of fat component [9]. Bresdenyuk found that the students of 17-21 years of age who have "low" and "normal" contents of the fat component have "excellent" level of aerobic capabilities according to the criterion Ya.P. Pyarnat [10]. Neha Parve et al showed the relationship between height, body mass and age with $\mathrm{VO}_{2 \max }$ in women of the second mature age group [11]. Kanae Oda et al established negative correlation $\mathrm{VO}_{2 \max }$ with body fat percentage in Japanese men and women 30-52 years [12]. Setty et al found negative association of fat component with cardio-respiratory system functionality [13]. About negative effect of the fat 
component on the $\mathrm{VO}_{2 \max }$ in obese individuals is indicated in studies M.Pourhassan and co-authors [14]. Payam Heydari et al found that demographic variables and BMI are factors that influence the determination of maximum oxygen consumption [15]. Daniel Bunout et al found that body mass without fat in men is an important predictor of maximum oxygen consumption [16].

Kaur et al point out that with the age in urban women of Punjab of age 50-80 years, the endomorphic and mesomorphic components decreases [17]. The variability of the component body composition in the process of human ontogenesis is shown by Sallnikova's study. The author argues that in the period of ontogenesis from 30 to 40 years in women, the fat component increases, and the muscle component decreases [18]. In view of the variability of the body components in the process of human ontogenesis, it is important to obtain data on all age groups.

Hypothesis: The study of maximum oxygen consumption and the body components of men in the first period of mature age will allow to determine the peculiarities of their manifestation, depending on the somatotype. Investigation of the correlation relations between the components of the body and $\mathrm{VO}_{2}$ max will reveal the influence of each of the components on the aerobic capacity of men aged 25-35 years.

Purpose: to detect the peculiarities of manifestation of maximum oxygen consumption of men with different somatotypes and to investigate the relationship with the component composition of the body.

\section{Material and Methods}

Participants.

The study involved 150 men aged $25-35$ years. In all subjects identified somatotype, VO2 max, component body composition. All subjects gave written consent to participate in the experiment.

Procedure.

The somatotype was determined by the HeathCarter method [19]. For this purpose, the following anthropometric studies were performed: they determined height, body mass, girth dimensions, transverse diameters and thickness of skin-fat foods. Each component was expressed in numerical value. The membership of the somatotype was determined by the advantage of the component at 2,5 points. In the absence of such an advantage, the somatotype of the person was defined as balanced. Participants were conventionally divided into groups by belonging to the somatotype.

Component composition of the body was determined by the method of bioelectric impedance using the OMRON BF-511. The device determined the percentage of fatty tissue in the body (subcutaneous fat), the percentage of skeletal muscle in the body, the percentage of visceral fat, body mass index (BMI), and body mass.

The indicator of maximum oxygen consumption $\left(\mathrm{VO}_{2}\right.$ ) was determined by the method of Carpman et al [20]. The men performed two loads on an ergometer for 5 minutes each (interval of rest -3 minutes). The pedaling speed was 60 turnovers per $\min ^{-1}$. The power of the first load was $1 \mathrm{~W}$ per $1 \mathrm{~kg}$ of body mass. The power of the second load was $2 \mathrm{~W}$ per $1 \mathrm{~kg}$ of body mass. At the end of each load, the heart rate was recorded. The mathematical calculations were used to determine the value of the indicator $\mathrm{VO}_{2 \max }$. $\mathrm{VO}_{2 \text { max }}$ was displayed in $\mathrm{ml} \mathrm{min}^{-1}$.

Compared the average group values of the indicators among representatives of different somatotype groups and group of men, which included all participants.

A correlation analysis of the absolute and relative $\mathrm{VO}_{2}$ ${ }_{\max }$ values with the fat and muscle components of the body was performed.

\section{Statistical analysis.}

The statistical analysis of the data was using the Excel 2010 program. The independent samples were compared for the analysis of the studied measures. Ranks of distribution displayed indicators features according to men's somatotypes. Statistical processing was performed applying Student's t-criterion. It was defined as an average mean $(X)$, Student's t-criterion $(t)$, standard error of the mean $( \pm \mathrm{m})$, number of degrees of freedom (f), significance value $(\mathrm{p})$. The difference was considered significant at $\mathrm{p}<0,05$.

The correlation analysis was performed to determine the interrelation between the studied measures. The correlation coefficient (r) was defined. The number of degrees of freedom $(\mathrm{k})$ was calculated. The $a-$ is the tabular coefficient of correlation which corresponds to the certain level of significance and calculated by means of tabular data. The significance of correlation coefficient was checked in comparison the obtained data with tabular. The connection considered significant at $\mathrm{p}<$ 0,05 . The gradation proposed by Cheddok was applied for the determination of constraint force. According to this technique the constraint force was estimated as follows: $0,1 \leq \mathrm{r}<0,3$-weak; $00,3 \leq \mathrm{r}<0,5$ - moderate; $0,5 \leq \mathrm{r}<$ 0,7 - average; $0,7 \leq \mathrm{r}<0,9-$ high; $0,9 \leq \mathrm{r} \leq 0,99$ - very high.

Experimental studies are in accordance with the directive of the Helsinki Declaration of the World Medical Association on ethical principles of medical research with human participation as the object of study (Protocol of the Commission on Bioethics at Vinnytsia State Pedagogical University No. 10 of 21.11.2018)

\section{Results}

The absolute indicator of $\mathrm{VO}_{2 \max }$ in men of the mesomorphic somatotype is higher value relative to the representatives of the ectomorphic somatotype. According to the relative indicator of $\mathrm{VO} 2 \mathrm{max}$, the representatives of ectomorphic and balanced somatotypes have higher values, while the lowest ones are representatives of the endomorphic-mesomorphic somatotype (Table 1).

In men with endomorphic-mesomorphic somatotype revealed significantly bigger of the body mass, a significantly highest percentage of fat component and visceral fat, among men of different somatotypes. Representatives of mesomorphic somatotype have the highest percentage of muscle component (Table 2). 
Table 1. Maximum oxygen consumption of men with different somatotypes aged 25-35

\begin{tabular}{|c|c|c|c|c|c|c|c|c|}
\hline \multirow[t]{2}{*}{ Indicators } & \multicolumn{2}{|c|}{$\begin{array}{l}\text { Representatives of } \\
\text { the mesomorphic } \\
\text { somatotype } \\
n=39\end{array}$} & \multicolumn{2}{|c|}{$\begin{array}{l}\text { Representatives of } \\
\text { the ectomorphic } \\
\text { somatotype } \\
n=32\end{array}$} & \multicolumn{2}{|c|}{$\begin{array}{l}\text { Representatives of } \\
\text { the endomorphic- } \\
\text { mesomorphic } \\
\text { somatotype } \\
n=37\end{array}$} & \multicolumn{2}{|c|}{$\begin{array}{l}\text { Representatives of } \\
\text { balanced somatotype } \\
n=42\end{array}$} \\
\hline & $\overline{\mathrm{X}}$ & $\mathrm{m}$ & $\overline{\mathrm{X}}$ & $m$ & $\overline{\mathrm{X}}$ & m & $\overline{\mathrm{X}}$ & $m$ \\
\hline $\begin{array}{l}\mathrm{VO}_{2 \max } \\
\left(\mathrm{ml} \cdot \mathrm{min}^{-1}\right)\end{array}$ & $\begin{array}{l}2809.7 \\
*\end{array}$ & 26.02 & 2680.7 & 44.19 & 2776.8 & 22.04 & 2792.1 & 47.06 \\
\hline $\mathrm{VO}_{2 \max }$ & 40.2 & 0.46 & 43.5 & 0.52 & 37.3 & 0.77 & 42.8 & 0.80 \\
\hline \multirow[t]{3}{*}{$\left(\mathrm{ml} \cdot \mathrm{min} \cdot \mathrm{kg}^{-1}\right)$} & $\bullet \bullet$ & & $\bullet \bullet \bullet$ & & & & ০০ & \\
\hline & & & ০০০ & & & & $\bullet \bullet \bullet$ & \\
\hline & & & $\square \square$ & & & & $\square$ & \\
\hline
\end{tabular}

Notes: The statistically significant difference: ${ }^{*}$ - in relation to the ectomorphic somatotype; $\circ$ - in relation to the mesomorphic somatotype; $\bullet-$ in relation to the endomorphic- mesomorphic somatotype; $\square-$ in relation to the all participants. The number of marks $\left(0,{ }^{*}, \bullet, \square\right)$ corresponds: 1 mark $-(p<0,05), 2$ marks $-(p<0,01), 3$ marks $-(p<$ 0,001).

Generalize the data in Table 1 and Table 2, we notice the following trends. The lowest value of the relative VO2 max indicator was found in men with endomorphicmesomorphic somatotype, who have the highest percentage of subcutaneous fat in the body, the highest percentage of visceral fat and the largest body mass.

Men who belong to the ectomorphic somatotype have higher values of relative $\mathrm{VO}_{2 \text { max }}$ indicator, lower percentage of subcutaneous fat in the body, lower percentage of visceral fat, less body mass and body mass index.

The revealed trends have led us to put forward the hypothesis that for men of certain somatotypes, the lower values of the relative $\mathrm{VO}_{2 \text { max }}$ indicator are due to high values of the percentage of fat component, visceral fat, body mass, and body mass index. To test the hypothesis, we conducted a correlation analysis between $\mathrm{VO}_{2 \text { max }}$ and body mass, body mass index, components of body composition in men with different somatotypes (Table 3 ).

The correlation analysis revealed a high degree of inverse relationship of the relative $\mathrm{VO}_{2 \text { max }}$ indicator with body mass in men with a mesomorphic somatotype; a high degree of inverse relationship of relative $\mathrm{VO}_{2}$ indicator with a body mass and BMI in men with endomorphic-mesomorphic somatotype; a high degree of inverse correlation of the relative $\mathrm{VO}_{2 \text { max }}$ indicator with a body mass in the male group, which brings together representatives of all somatotypes.

\section{Discussion}

Thus, it can be argued that in men with mesomorphic and endomorphic-mesomorphic somatotype a greater body mass causes lower relative $\mathrm{VO}_{2}$ max indicator. In addition, in men with endomorphic-mesomorphic somatotype, the low values of the relative $\mathrm{VO}_{2 \max }$ indicator are associated with high BMI values. Representatives of somatotypes that are characterized by a smaller body mass (ectomorphic and balanced) have a lower degree of inverse relationship of body mass with a relative $\mathrm{VO}_{2 \max }$ indicator. The influence of muscle and fat components, $\mathrm{BMI}$ on the level of $\mathrm{VO}_{2 \max }$ in representatives of balanced and ectomorphic somatotypes smaller, because the strength of the correlation between these indicators is characterized as noticeable, moderate, or correlation is absent.

The data we received about lower relative $\mathrm{VO}_{2}$ indicator men 25-35 years of mesomorphic and endomorphic-mesomorphic somatotype is new. In the scientific literature, there is evidence of the significant role of somatotype components in influencing to exhibit aerobic productivity. Rupasinghe et al found that endomorphism-dominated medical students were found to have low $\mathrm{VO}_{2 \text { max }}$ levels [7]. Marangoz İrfan et al established a high degree of negative correlation between $\mathrm{VO}_{2 \max }$ and endomorphism in handball players of 18-30 years; a marked degree of positive correlation between $\mathrm{VO}_{2 \max }$ and ectomorphism [21]. Himel Mondal \& Snigdha Prava Mishra showed of negative influence of Increasing waist size and Waist-to-height index on $\mathrm{VO}_{2 \max }$ of men 17-25 years [22].

Studies performed by Manmohan Sharma et al found in men of 25-35 years old a very high degree of inverse relationship between the percentage of subcutaneous fat and the relative $\mathrm{VO}_{2 \max }$ indicator. These authors also found a high degree of inverse relationship between BMI and relative $\mathrm{VO}_{2 \text { max }}$ indicator [9]. The data obtained by us indicate a noticeable degree of the inverse relationship of the relative $\mathrm{VO}_{2 \text { max }}$ indicator with a percentage of subcutaneous fat and a moderate inverse correlation with BMI. According to the established trends, the results of our research coincide with the data of the abovementioned authors. The only difference is the degree of 
Table 2. Component body composition and body mass in men aged 25-35 with different somatotype

\begin{tabular}{|c|c|c|c|c|c|c|c|c|c|c|}
\hline \multirow[t]{2}{*}{ Indicators } & \multicolumn{2}{|c|}{$\begin{array}{l}\text { All participant } \\
\text { (representatives } \\
\text { of all } \\
\text { somatotypes) } \\
n=150\end{array}$} & \multicolumn{2}{|c|}{$\begin{array}{l}\text { Representatives } \\
\text { of the } \\
\text { mesomorphic } \\
\text { somatotype } \\
n=39\end{array}$} & \multicolumn{2}{|c|}{$\begin{array}{l}\text { Representatives } \\
\text { of the } \\
\text { ectomorphic } \\
\text { somatotype } \\
n=32\end{array}$} & \multicolumn{2}{|c|}{$\begin{array}{l}\text { Representatives } \\
\text { of the } \\
\text { endomorphic- } \\
\text { mesomorphic } \\
\text { somatotype } \\
n=37\end{array}$} & \multicolumn{2}{|c|}{$\begin{array}{l}\text { Representatives } \\
\text { of balanced } \\
\text { somatotype } \\
n=42\end{array}$} \\
\hline & $\overline{\mathrm{X}}$ & $\mathrm{m}$ & $\overline{\mathrm{X}}$ & $\mathrm{m}$ & $\overline{\mathrm{X}}$ & $\mathrm{m}$ & $\overline{\mathrm{X}}$ & $\mathbf{m}$ & $\overline{\mathrm{X}}$ & $\mathrm{m}$ \\
\hline $\begin{array}{l}\text { Fat component, } \\
\%\end{array}$ & $\begin{array}{l}16.6 \\
* * * \\
\circ 00\end{array}$ & 0.35 & $\begin{array}{l}14.7 \\
* * *\end{array}$ & 0.32 & 11.0 & 0.28 & $\begin{array}{l}23.9 \\
\square \square \square \\
\infty 00 \\
\square \square \\
* * *\end{array}$ & 0.31 & $\begin{array}{l}16.2 \\
* * * \\
0\end{array}$ & 0.56 \\
\hline $\begin{array}{l}\text { Muscle } \\
\text { component, \% }\end{array}$ & $\begin{array}{l}41.0 \\
\bullet \bullet \bullet \\
\text { 口 }\end{array}$ & 0.25 & $\begin{array}{l}44.6 \\
\bullet \bullet \bullet \\
\text { घu} \\
\square \square \square \\
* * *\end{array}$ & 0.42 & 40.7 & 0.38 & 38.7 & 0.33 & 39.7 & 0.52 \\
\hline Visceral fat, \% & $\begin{array}{l}3.5 \\
* * * \\
\square\end{array}$ & 0.23 & $\begin{array}{l}3.2 \\
* * *\end{array}$ & 0.34 & 1.6 & 0.04 & $\begin{array}{l}6.2 \\
000 \\
\square m \\
\square \square \square \\
* * *\end{array}$ & 0.46 & $\begin{array}{l}2.9 \\
* * *\end{array}$ & 0.14 \\
\hline Body mass, kg & $\begin{array}{l}68.3 \\
* * * \\
\end{array}$ & 0.96 & $\begin{array}{l}70.1 \\
* * * \\
\mathbf{m}\end{array}$ & 0.87 & 61.7 & 0.88 & $\begin{array}{l}75.2 \\
* * * \\
\mathbf{\square} \\
\square \square \\
0\end{array}$ & 1.91 & $\begin{array}{l}65.5 \\
* *\end{array}$ & 0.91 \\
\hline $\mathrm{BMI}, \mathrm{kg} / \mathrm{m}^{2}$ & $\begin{array}{l}22.4 \\
* * *\end{array}$ & 0.72 & $\begin{array}{l}23.2 \\
* * *\end{array}$ & 0.26 & 18.9 & 0.11 & $\begin{array}{l}24.5 \\
* * * \\
0 \\
\square\end{array}$ & 0.51 & $\begin{array}{l}22.4 \\
*\end{array}$ & 1.54 \\
\hline
\end{tabular}

Notes: The statistically significant difference: ${ }^{*}$ - in relation to the ectomorphic somatotype; 0 - in relation to the mesomorphic somatotype; - - in relation to the balanced somatotype; - - in relation to the endomorphicmesomorphic somatotype; $\square-$ in relation to the all participants. The number of marks $(0, *, \bullet, \square)$ corresponds: 1 mark $-(p<0,05), 2$ marks - $(p<0,01), 3$ marks - $(p<0,001)$.

correlation. This difference may be due to the fact that the authors used the step-method to determine $\mathrm{VO}_{2 \max }$, and in our research the method of bicycle ergometry was used. Also, the difference in results may be due to the region's characteristics of the residence of the participants. Consideration should also data obtained by Christina Grüne et al who found that obesity affects the growth of error in determining $\mathrm{VO}_{2 \text { max }}$ by not a direct method [23].

Studies performed by Mondal \& Mishra found in men of 18-25 years moderate degree of negative correlation
BMI with relative $\mathrm{VO}_{2 \text { max }}$ indicator and a high degree of negative correlation between the percentage of subcutaneous fat and the relative value of $\mathrm{VO}_{2 \max }$ indicator [24]. Marcin Maciejczyk et al found a moderate degree of negative correlation in men of 18-30 years between the relative $\mathrm{VO}_{2 \text { max }}$ indicator and body mass, BMI, fat component, and the lack of correlation with the muscle component. In addition, they found a moderate degree of positive correlation between the absolute value of $\mathrm{VO}_{2}$ ${ }_{\max }$ and the muscular component. The authors argue that 
Table 3. Correlation ratio of maximum oxygen consumption indicators with component composition of the body, body mass of men aged 25-35

\begin{tabular}{|c|c|c|c|c|c|c|c|c|c|c|}
\hline \multirow[t]{2}{*}{ Indicators } & \multicolumn{2}{|c|}{ Fat component } & \multicolumn{2}{|c|}{$\begin{array}{l}\text { Muscle } \\
\text { component }\end{array}$} & \multicolumn{2}{|c|}{ Visceral fat } & \multicolumn{2}{|c|}{ Body mass } & \multicolumn{2}{|c|}{ Body mass index } \\
\hline & $r$ & $\mathbf{p}$ & $r$ & $\mathbf{p}$ & $r$ & $\mathbf{p}$ & $r$ & p & $r$ & $\mathbf{p}$ \\
\hline \multicolumn{11}{|c|}{ mesomorphic somatotype, $\mathrm{n}=39$} \\
\hline $\mathrm{VO}_{2 \text { max, abs. }}$ & -0.035 & $\begin{array}{l}p> \\
0.05\end{array}$ & -0.033 & $\begin{array}{l}p> \\
0.05\end{array}$ & 0.346 & $\begin{array}{l}\mathrm{p}< \\
0.05\end{array}$ & 0.565 & $\begin{array}{l}p< \\
0.05\end{array}$ & 0.394 & $p<0.05$ \\
\hline $\mathrm{VO}_{2 \max , \text { rel. }}$ & -0.241 & $\begin{array}{l}p> \\
0.05\end{array}$ & 0.241 & $\begin{array}{l}p> \\
0.05\end{array}$ & -0.132 & $\begin{array}{l}p> \\
0.05\end{array}$ & -0.717 & $\begin{array}{l}p< \\
0.05\end{array}$ & -0.341 & $p<0.05$ \\
\hline \multicolumn{11}{|c|}{ ectomorphic somatotype, $\mathbf{n}=32$} \\
\hline $\mathrm{VO}_{2 \text { max, abs. }}$ & -0.149 & $\begin{array}{l}p> \\
0.05\end{array}$ & 0.326 & $\begin{array}{l}p> \\
0.05\end{array}$ & -0.123 & $\begin{array}{l}p> \\
0.05\end{array}$ & 0.677 & $\begin{array}{l}p< \\
0.05\end{array}$ & 0.391 & $p<0.05$ \\
\hline $\mathrm{VO}_{2 \text { max, rel. }}$ & -0.109 & $\begin{array}{l}p> \\
0.05\end{array}$ & 0.338 & $\begin{array}{l}p> \\
0.05\end{array}$ & -0.431 & $\begin{array}{l}p< \\
0.05\end{array}$ & -0.372 & $\begin{array}{l}p< \\
0.05\end{array}$ & -0.220 & $p>0.05$ \\
\hline \multicolumn{11}{|c|}{ endomorphic- mesomorphic somatotype, $n=37$} \\
\hline $\mathrm{VO}_{2 \max , \text { abs. }}$ & 0.086 & $\begin{array}{l}p> \\
0.05\end{array}$ & -0.125 & $\begin{array}{l}p> \\
0.05\end{array}$ & 0.161 & $\begin{array}{l}p> \\
0.05\end{array}$ & 0.398 & $\begin{array}{l}p< \\
0.05\end{array}$ & 0.228 & $p>0.05$ \\
\hline $\mathrm{VO}_{2 \text { max, rel. }}$ & -0.430 & $\begin{array}{l}p< \\
0.05\end{array}$ & 0.222 & $\begin{array}{l}p> \\
0.05\end{array}$ & -0.520 & $\begin{array}{l}\mathrm{p}< \\
0.05\end{array}$ & -0.878 & $\begin{array}{l}p< \\
0.05\end{array}$ & -0.783 & $\mathrm{p}<0.05$ \\
\hline \multicolumn{11}{|c|}{ balanced somatotype, $n=42$} \\
\hline $\mathrm{VO}_{2 \max , \text { abs. }}$ & -0.080 & $\begin{array}{l}p> \\
0.05\end{array}$ & 0.168 & $\begin{array}{l}p> \\
0.05\end{array}$ & 0.035 & $\begin{array}{l}p> \\
0.05\end{array}$ & 0.309 & $\begin{array}{l}p< \\
0.05\end{array}$ & 0.030 & $p>0.05$ \\
\hline $\mathrm{VO}_{2 \text { max, rel. }}$ & -0.521 & $\begin{array}{l}p< \\
0.05\end{array}$ & 0.292 & $\begin{array}{l}p> \\
0.05\end{array}$ & -0.580 & $\begin{array}{l}p< \\
0.05\end{array}$ & -0.601 & $\begin{array}{l}p< \\
0.05 \\
\end{array}$ & -0.024 & $p>0.05$ \\
\hline \multicolumn{11}{|c|}{ all participants (representatives of all somatotypes), $n=150$} \\
\hline $\mathrm{VO}_{2 \max , \text { abs. }}$ & 0.061 & $\begin{array}{l}p> \\
0.05\end{array}$ & 0.125 & $\begin{array}{l}p> \\
0.05\end{array}$ & 0.151 & $\begin{array}{l}p> \\
0.05\end{array}$ & 0.412 & $\begin{array}{l}p< \\
0.05\end{array}$ & 0.174 & $p>0.05$ \\
\hline $\mathrm{VO}_{2 \text { max, rel. }}$ & -0.596 & $\begin{array}{l}p< \\
0.05\end{array}$ & 0.183 & $\begin{array}{l}\mathrm{p}< \\
0.05\end{array}$ & -0.621 & $\begin{array}{l}p< \\
0.05\end{array}$ & -0.786 & $\begin{array}{l}p< \\
0.05\end{array}$ & -0.364 & $p<0.05$ \\
\hline
\end{tabular}

Notes: $\mathrm{VO}_{2 \text { max, abs. }}$ - absolute indicator of maximum oxygen consumption; $\mathrm{VO}_{2 \text { max, rel. }}$ - relative indicator of maximum oxygen consumption; $r$ - coefficient of correlation; $p$ - statistical significance for correlation.

low values of relative $\mathrm{VO}_{2 \text { max }}$ indicator are due to high body mass values, regardless of whether the fat or muscle component has an advantage [25]. The results of our research agree with this statement. Thus, it can be argued that there is a negative correlation between body mass, $\mathrm{BMI}$, percentage of subcutaneous fat with relative $\mathrm{VO}_{2}$ indicator in men without somatotype consideration. However, according to various data, the degree of these correlation ranges from moderate to very high.

\section{Conclusions}

We have established the features of the manifestation of maximum oxygen consumption in men 25-35 years with different somatotypes. For representatives of the mesomorphic and endomorphic-mesomorphic somatotype, a larger body mass and a high degree of correlation between body mass and relative $\mathrm{VO}_{2}$ max indicator are characteristic. For representatives of the ectomorphic and balanced somatotype, a smaller body mass and a lower degree of correlation between body mass and relative $\mathrm{VO}_{2 \text { max }}$ indicator max are characteristic.

\section{Conflict of interest}

The authors state that there is no conflict of interest. 


\section{Reference}

1. Furman Yu, Miroshnichenko V, Drachuk S. Perspective models of physical training and health technologies in physical education of students of higher educational institutions. Kiev: Olympic literature; 2013. (in Ukrainian).

2. Miroshnichenko V, Salnykova S, Bohuslavska V, Pityn M, Furman Yu, Iakovliv V, Semeryak Z. Enhancement of physical health in girls of 17-19 years by adoption of physical loads taking their somatotype into account. Journal of Physical Education and Sport, 2019; 19 (Suppl.issue 2): 387-92.

3. Furman Iu, Miroshnichenko V, Brezdeniuk O. Standards for assessing the aerobic and anaerobic productivity of young people aged 17-19 living in the Podilsk region. Vinnitsa; 2019. (in Ukrainian).

4. Yoo-Rim Choi, Wan-Suk Choi. Impacts of Korean Somatotype in Energy Consumption and Hormone Changes During Treadmill Gait -Around University Students. The Journal of Korean Society of Physical Therapy. 2011: 85-92.

5. Goran Spori, Daniel Bok, Dinko Vuleta Jr, Dra'en Harasin. Impact of Body Composition on Performance in Fitness Tests among Personnel of the Croatian Navy. Coll. Antropol. 2011; 35(2): 335-9.

6. Alkandari, JR, Barac Nieto M. Somatotype Components, Aerobic Fitness and Grip Strength in Kuwaiti Males and Females. Health. 2016; 8: 1349-55. https://doi.org/10.4236/health.2016.813135

7. Rupasinghe SD, Samarakoon KM, Samarakoon SM, Rathnayake RM, Samarakoon NK, Samarasinghe PR, et al. Distribution of somatotypes between categories of $\mathrm{VO}_{2}$ among a selected group of individuals. Proceedings Peradeniya University International Research Sessions. 2014 July 4-5. University of Peradeniya; 2014.

8. Sukanta S. Somatic and Body Composition Factors Underlying Aerobic Capacity. American Journal of Sports Science, 2015; 3(2): 36-40. https://doi.org/10.11648/j.ajss.20150302.12

9. Manmohan Sharma, Kamal RB, Kavita Chawla. Correlation of body composition to aerobic capacity; A cross sectional study. International Journal of Applied Research. 2016; 2(1): 38-42.

10. Brezdeniuk O. Aerobic potentials of 17-21 years old students with different component composition of body mass. Physical Activity, Health and Sport. 2014; 1(15): 9-18. (in Ukrainian).

11.Neha Parve, Madhuri Kulkarni, Hemangini Sarambekar. Study of Static Anthropometric Measurements and Body Somatotypes of Women. International Journal of Scientific and Research Publications, 2015;5(9):1-5.

12.Oda K, Miyatake N, Sakano N, Saito T, Miyachi M, Tabata I, et al. Relationship between peak oxygen uptake and regional body composition in Japanese subjects. Journal of Sport and Health Science, 2014;3:233-8. https://doi.org/10.1016/j.jshs.2012.11.006

13.Setty P, Padmanabha B, Doddamani B. Correlation between obesity and cardio respiratory fitness.
Int J Med Sci Public Health. 2013; 2(2): 300-4. https://doi.org/10.5455/ijmsph.2013.2.298-302

14.Pourhassan M, Eggeling B, Schautz B, Johannsen M, Kiosz D, Glüer CC, et al. Relationship between submaximal oxygen uptake, detailed body composition, and resting energy expenditure in overweight subjects. Am $J$ hum Biol. 2015;27: 397-406. https://doi.org/10.1002/ajhb.22666

15.Payam Heydari, Sakineh Varmazyar, Ahmad Nikpey, Ali Safari Variani, Mojtaba Jafarvand. Step Test: a method for evaluating maximum oxygen consumption to determine the ability kind of work among students of medical emergencies. Electron Physician. 2017; 9(3): 4020-6. https://doi.org/10.19082/4020

16.Daniel Bunout, Gladys Barrera, Sandra Hirsch, Teresa Jimenez, María Pia de la Maza. Association between activity energy expenditure and peak oxygen consumption with sarcopenia. BMC Geriatrics. 2018; 18: 298. https://doi.org/10.1186/s12877-018-0993-y

17.Kaur G, Singh S, Singh A. Age Related Variations in Endomorphic, Mesomorphic and Ectomorphic Components of Somatotype in Urban Women of Punjab. Human Biology Review. 2017; 6(1): 47-52.

18.Sal'nikova S. Physical state improvement of women aged 30-49 by complex application of aqua-fitness and endogenic hypoxic respiration method. [dissertation]. Ivano-Frankivsk; 2016. (in Ukrainian).

19.Carter J, Heath B. Somatotyping -development and applications. Cambridge University Press; 1990

20.Karpman V, Belocerkovkij Z, Gudkov I. The study of physical performance in an athlete. Moscow: Physical Culture and Sports; 1974. (in Russian)

21.Marangoz İrfan, Var Sevde Mavi. The Relationship among Somatotype Structures, Body Compositions and Estimated Oxygen Capacities of Elite Male Handball Players. Asian Journal of Education and Training, 2018; 4(3): 216-9. https://doi.org/10.20448/journal.522.2018.43.216.219

22.Himel Mondal, Snigdha Prava Mishra. Correlation of waist circumference and waist-to-height ratio with maximal aerobic capacity in young adults. Journal of Health Research and Reviews, 2017; 4: 62-5. https://doi.org/10.4103/jhrr.jhrr 517

23.Christina Grüne de Souza e Silva, Barry A Franklin, Claudio Gil Soares de Araújo. Influence of central obesity in estimating maximal oxygen uptake. Clinics. 2016; 71 (11): 629-34. https://doi.org/10.6061/clinics/2016(11)02

24.Mondal H, Mishra SP. Effect of BMI, Body Fat Percentage and Fat Free Mass on Maximal Oxygen Consumption in Healthy Young Adults. Journal of Clinical and Diagnostic Research. 2017; 11(6): 17-20. https://doi.org/10.7860/JCDR/2017/25465.10039

25.Maciejczyk M, Więcek M, Szymura J, Szyguła Z, Wiecha S, Cempla J. The Influence of Increased Body Fat or Lean Body Mass on Aerobic Performance. PLoS ONE, 2014;9:e95797. https://doi.org/10.1371/journal.pone.0095797 


\section{Information about the authors:}

Viacheslav M. Miroshnichenko: (Corresponding Author); https://orcid.org/0000-0003-1139-4554;29miroshnichenko@gmail. com; Department of Physical Education, Faculty of Physical Education, Vinnytsia Mykhailo Kotsiubynskyi State Pedagogical University; Ostroz'koho st., 32, Vinnytsia, 21100, Ukraine.

Yuriy M. Furman: https://orcid.org/0000-0002-5206-7712; furman-dok@ukr.net; Department of Medical and Biological Foundations of Physical Education and Physical Rehabilitation, Faculty of Physical Education, Vinnytsia Mykhailo Kotsiubynskyi State Pedagogical University; Ostroz'koho st., 32, Vinnytsia, 21100, Ukraine.

Oleksandra Yu. Brezdeniuk: http://orcid.org/0000-0003-0844-8777; sandrikk86@gmail.com; Department of Physical Education, Faculty of Physical Education, Vinnytsia Mykhailo Kotsiubynskyi State Pedagogical University; Ostroz'koho st., 32, Vinnytsia, 21100, Ukraine.

Victoria E. Onyshchuk: http://orcid.org/0000-0002-9615-6653; Victiriaonichuk@gmail.com; Department of Medical and Biological Foundations of Physical Education and Physical Rehabilitation, Faculty of Physical Education, Vinnytsia Mykhailo Kotsiubynskyi State Pedagogical University; Ostroz'koho st., 32, Vinnytsia, 21100, Ukraine.

Natalia V. Gavrylova: https://orcid.org/0000-0001-6209-5875; gavrilova.natal83@gmail.com; Department of Medical and Biological Foundations of Physical Education and Physical Rehabilitation, Faculty of Physical Education, Vinnytsia Mykhailo Kotsiubynskyi State Pedagogical University; Ostroz'koho st., 32, Vinnytsia, 21100, Ukraine.

Svitlana V. Salnykova: https://orcid.org/0000-0003-4675-6105; aqvasveta@ukr.net; Department of Physical Education, Vinnytsia Institute of Trade and Economics of Kyiv National University of Trade and Economics; Soborna st., 87, Vinnytsia, 21050, Ukraine.

Cite this article as:

Miroshnichenko VM, Furman YM, Brezdeniuk OYu, Onyshchuk VE, Gavrylova NV, Salnykova SV. Correlation of maximum oxygen consumption with component composition of the body, body mass of men with different somatotypes aged 25-35. Pedagogy of Physical Culture and Sports, 2020;24(6):290-296.

https://doi.org/10.15561/26649837.2020.0603

This is an Open Access article distributed under the terms of the Creative Commons Attribution License, which permits unrestricted use, distribution, and reproduction in any medium, provided the original work is properly cited (http://creativecommons.org/licenses/by/4.0/deed.en).

Received: 15.05 .2020

Accepted: 01.07.2020; Published: 30.12 .2020 